\title{
SUBSTRATOS NA PRODUÇÃO DE MUDAS DE MANGABEIRA EM TUBETES ${ }^{1}$
}

\author{
Elisângela Aparecida da Silva², Alessandra Conceição de Oliveira ${ }^{3}$, Vander Mendonça ${ }^{4}$, Flávio Meneses Soares ${ }^{2}$
}

\section{ABSTRACT \\ USE OF SUBSTRATES FOR GROWING \\ Hancornia speciosa Gomes SEEDLINGS IN PLASTIC TUBES}

Mangabeira (Hancornia speciosa Gomes) is a native fruit species from the Brazilian savannah. Its sexual propagation depends on a suitable substrate, because it interferes with seed germination and seedling establishment. The objective of this study was to evaluate the effect of different substrates for growing mangabeira seedlings in plastic tubes. The experiment was carried out in a greenhouse, in Cassilândia, Mato Grosso do Sul State, Brazil. The experimental design used was randomized blocks, with four replications and 15 seeds per plot. Five substrates were evaluated: A (washed sand + Plantmax ${ }^{\circledR}+$ soil, 1:1:3 $\mathrm{v}: \mathrm{v}: \mathrm{v}), \mathrm{B}$ (carbonized rice husk + Plantmax $^{\circledR}+$ soil, 1:1:3), C (carbonized rice husk + earthworm humus + soil, 1:1:3), D (bovine manure + Plantmax $^{\circledR}+$ soil, 1:1:3), and E (bovine manure + soil, $2: 3)$. The following parameters were evaluated: plant emergence percentage, emergence speed index, mortality percentage, seedling height, stem diameter, root length, number of leaves, chlorophyll leaf index, and shoot, root, and whole plant dry mass. From the results, substrates C, D, and E can be used for growing mangabeira seedlings in plastic tubes.

KEY-WORDS: Hancornia speciosa Gomes; Brazilian savannah; native fruit trees.

\section{INTRODUÇÃO}

As espécies frutíferas nativas do Brasil, encontradas em diversas regiões, tais como o Cerrado, a Caatinga e a Região Amazônica, são de ocorrência espontânea, exploradas localmente e, na maioria das vezes, de forma extrativista (Ferreira 1999). Mesmo existindo plantios racionais e tecnificados, muitas espécies são desconhecidas, apesar do grande potencial destas culturas (Lederman et al. 2000).

\section{RESUMO}

A mangabeira (Hancornia speciosa Gomes) é uma espécie frutífera nativa do Cerrado brasileiro. A propagação sexuada desta espécie depende de um substrato adequado, pois o mesmo interfere no processo germinativo e no estabelecimento da muda. Objetivou-se estudar o efeito de diferentes substratos na produção de mudas de mangabeira em tubetes. O trabalho foi conduzido em casa-de-vegetação, em Cassilândia (MS). O delineamento experimental foi em blocos casualizados, com quatro repetições e 15 plantas por parcela. Foram utilizados os seguintes substratos: A (areia lavada + Plantmax ${ }^{\circledR}+$ solo, na proporção de 1:1:3 v:v:v), B (casca de arroz carbonizada + Plantmax $^{\circledR}+$ solo, 1:1:3), C (casca de arroz carbonizada + húmus de minhoca + solo, 1:1:3), D (esterco bovino + Plantmax $^{\circledR}+$ solo, 1:1:3) e E (esterco bovino + solo, 2:3). Avaliou-se a percentagem de emergência de plântulas, índice de velocidade de emergência, percentagem de mortalidade, altura da muda, diâmetro do colo, comprimento do sistema radicular, número de folhas, índice de clorofila foliar e massa seca da parte aérea, do sistema radicular e total. De acordo com os resultados obtidos, os substratos C, D e E podem ser utilizados para a produção de mudas de mangabeira em tubetes.

PALAVRAS-CHAVE: Hancornia speciosa Gomes; Cerrado; frutíferas nativas.

Neste contexto, sugere-se a exploração econômica de fruteiras nativas, por meio da manutenção da produtividade e integridade ambiental, que, além de reverter o processo de degradação das terras, gera renda ao produtor, devido ao seu potencial aproveitamento alimentar, proteção ambiental e florestal, controle da erosão e conservação de rios e nascentes, bem como proteção e conservação de espécies animais e vegetais em vias de extinção (Melo 1999).

1. Trabalho recebido em mar./2010 e aceito para publicação em jun./2011 (n registro: PAT 9042/ DOI: 10.5216/pat.v41i2.9042).

2. Universidade Federal de Lavras (UFLa), Departamento de Agricultura, Lavras, MG, Brasil.

E-mails: agroelis@yahoo.com.br, flaviosoares.agricultura@gmail.com.

3. Universidade Estadual "Júlio de Mesquita Filho" (Unesp), Departamento de Engenharia Rural, Setor de Irrigação e Drenagem, Botucatu, SP, Brasil. E-mail: oliveira84@fca.unesp.br.

4. Universidade Federal Rural do Semiárido (Ufersa), Departamento de Ciências Vegetais, Setor de Fruticultura, Mossoró, RN, Brasil.E-mail: vander@ufersa.edu.br. 
A mangabeira (Hancornia speciosa Gomes) é uma destas fruteiras do Cerrado, a qual possui fruto extremamente apreciado, consumido in natura, além de ser utilizado na fabricação de refrescos, sorvetes, doces secos, compotas e no preparo de vinho e vinagre (Ferreira 1973, Parente et al. 1985, Aguiar Filho et al. 1998). Além do aproveitamento do fruto, a mangabeira pode ser explorada na produção de borracha (Paula 1992), que é utilizada na região dos Cerrados, na medicina popular, e, ainda, para impermeabilizar tecidos e confeccionar bolsas (Hirschmann \& Arias 1990).

Para sua expansão e plantio comercial, o primeiro passo é a obtenção de mudas sadias, que se estabeleçam em viveiros, o que garantirá a sanidade da planta no campo. O conhecimento sobre a diversidade genética da espécie e de aspectos relacionados à sua propagação é necessário e deve preceder a implantação de pomares (Rosa et al. 2005).

No processo de produção de mudas, o substrato interfere diretamente na qualidade das plantas, devido à variação das propriedades físicas, químicas e biológicas do mesmo. As características de estrutura, aeração, capacidade de retenção de água e grau de contaminação por patógenos, dentre outras, variam de acordo com o material utilizado na composição do substrato e podem afetar a germinação e o estabelecimento da plântula, nesta fase, o que demonstra a importância da escolha da composição ideal do substrato.

De acordo com Kämpf (2000), um substrato de qualidade pode ser formado por solo mineral ou orgânico ou, ainda, de diversos materiais, constituindo-se, assim, uma mistura, e deve apresentar equilíbrio adequado entre umidade e aeração, ser poroso o suficiente para permitir trocas gasosas eficientes, livre de patógenos ou micro-organismos saprófitos, isento de propágulos (sementes ou estruturas vegetativas) de invasoras, e de baixa densidade.

A produção de mudas de mangabeira, no tocante ao substrato, tem sido avaliada por alguns autores (Oliveira 1998, Vieira Neto 1998, Santos \& Nascimento 1999), levando-se em consideração a disponibilidade regional. De acordo com Vieira Neto (1994), a mangabeira não é exigente em fertilidade, pois vegeta bem em solos pobres e ácidos, características dos solos do Cerrado.

Objetivou-se estudar o efeito de diferentes substratos, na produção de mudas de mangabeira por sementes, em tubetes, visando-se à obtenção de mudas de qualidade, para estabelecimento a campo.

\section{MATERIAL E MÉTODOS}

O experimento foi instalado e conduzido de 04 de novembro de 2007 a 11 de abril de 2008, em casa-de-vegetação (cobertura de polietileno transparente e difusor de luz de 150 micras), na área experimental da Universidade Estadual do Mato Grosso do Sul (UEMS), Unidade Universitária de Cassilândia ( $19^{\circ} 05^{\prime} \mathrm{S}, 51^{\circ} 56^{\prime} \mathrm{W}$ e altitude de $\left.471 \mathrm{~m}\right)$. De acordo com a classificação climática de Köppen, o local apresenta Clima Tropical Chuvoso (Aw), com verão chuvoso e inverno seco (precipitação de inverno inferior a $60 \mathrm{~mm}$ ) (Silva et al. 2009). A temperatura média registrada no interior da casa-de-vegetação, durante o período de condução do experimento, foi de $26,8^{\circ} \mathrm{C}$, enquanto a temperatura média externa foi de $27,5^{\circ} \mathrm{C}$.

As sementes de mangaba foram adquiridas em propriedade particular localizada próxima à UEMS, coletadas de plantas adultas e sadias, na época de maturação dos frutos (novembro), quando os mesmos iniciaram queda natural. Os frutos foram despolpados manualmente, de acordo com recomendação de Barros (2006). As sementes foram lavadas em água corrente, até a completa remoção da mucilagem, para que fossem eliminadas possíveis substâncias inibidoras da germinação presentes na polpa.

A semeadura foi realizada logo em seguida, para que não ocorresse alteração da qualidade fisiológica (Barros 2006). Foram semeadas duas sementes por recipiente, a $1,5 \mathrm{~cm}$ de profundidade. Os recipientes utilizados foram tubetes com comprimento de $140 \mathrm{~mm}$, diâmetro superior de $40 \mathrm{~mm}$ e capacidade de $130 \mathrm{~cm}^{3}$.

Os tratamentos foram constituídos de cinco misturas de substratos: A (areia lavada + Plantmax ${ }^{\circledR}+$ solo, na proporção 1:1:3, em volume), B (casca de arroz carbonizada + Plantmax ${ }^{\circledR}+$ solo, 1:1:3), C (casca de arroz carbonizada + húmus de minhoca + solo, 1:1:3), D (esterco bovino + Plantmax ${ }^{\circledR}+$ solo, 1:1:3) e E (esterco bovino + solo, 2:3). O solo usado foi classificado como Neossolo Quartzarênico (Embrapa 1999), do qual se usou o horizonte B. Os substratos resultantes das misturas foram analisados quimicamente (Tabelas 1 e 2), sendo as análises realizadas pelo Instituto Agronômico de Campinas (IAC).

Utilizou-se o delineamento em blocos casualizados, com quatro repetições, totalizando 20 parcelas, com 15 plantas por parcela experimental, sendo todas as plantas consideradas na avaliação. 
Tabela 1. Resultados da análise química ${ }^{1}$ para macronutrientes, $\mathrm{pH}$ e condutividade elétrica $(\mathrm{CE})$ de substratos utilizados em experimento de produção de mudas de mangabeira em tubetes (Cassilândia, MS, 2008).

\begin{tabular}{|c|c|c|c|c|c|c|c|c|c|c|c|}
\hline \multirow{2}{*}{ Substratos $^{2}$} & \multirow{2}{*}{$\mathrm{pH}$} & $\mathrm{CE}$ & N-Nitrato & $\mathrm{P}$ & Cloreto & $\mathrm{S}$ & N-Amônia & $\mathrm{K}$ & $\mathrm{Na}$ & $\mathrm{Ca}$ & $\mathrm{Mg}$ \\
\hline & & $\mathrm{dS} \mathrm{m}^{-1}$ & & \multicolumn{8}{|c|}{$\mathrm{mg} \mathrm{L}^{-1}$} \\
\hline A & 5,3 & 0,2 & 4,1 & 0,0 & - & 15,9 & 2,3 & 11,7 & 4,8 & 11,9 & 8,6 \\
\hline B & 5,3 & 0,3 & 0,3 & 0,1 & - & 20,1 & 3,1 & 30,0 & 5,3 & 9,9 & 8,0 \\
\hline $\mathrm{C}$ & 7,6 & 0,3 & 0,1 & 3,7 & - & 7,7 & 1,3 & 79,1 & 10,3 & 6,8 & 8,1 \\
\hline $\mathrm{D}$ & 5,3 & 0,5 & 15,2 & 0,6 & - & 26,1 & 6,6 & 36,6 & 13,6 & 27,7 & 18,1 \\
\hline $\mathrm{E}$ & 4,9 & 0,4 & 33,8 & 0,2 & - & 1,6 & 1,7 & 38,1 & 12,8 & 34,8 & 15,5 \\
\hline
\end{tabular}

${ }^{1}$ Método de extração: 1:2 (Holanda). Métodos de determinação: N-(amoniacal e nitrato): destilação; K, Ca, Mg, P, S: ICP-OES; Nitrogênio Total Kjeldahl. ${ }^{2}$ Substrato A: areia lavada + Plantmax ${ }^{\circledR}+$ solo $(1: 1: 3 \mathrm{v}: \mathrm{v}: \mathrm{v})$. Substrato B: casca de arroz carbonizada + Plantmax ${ }^{\circledR}+$ solo $(1: 1: 3)$. Substrato C: casca de arroz carbonizada + húmus de minhoca + solo (1:1:3). Substrato D: esterco bovino + Plantmax ${ }^{\circledR}+$ solo (1:1:3). Substrato E: esterco bovino + solo (2:3).

A emergência teve início no $20^{\circ}$ dia após a semeadura e o desbaste foi realizado 15 dias após a emergência, deixando-se a plântula mais vigorosa por recipiente. A eliminação de plantas daninhas foi realizada manualmente, conforme a necessidade. A irrigação foi realizada por sistema de microaspersão ( 5 vezes, por 5 minutos), do momento da semeadura até 30 dias após a semeadura. Após este período, irrigou-se duas vezes por dia (manhã e tarde), com auxílio de um regador manual, até a finalização do experimento.

Após a semeadura e início da emergência de plântulas, procedeu-se à avaliação do índice de velocidade de emergência (IVE) (Maguirre 1962), sendo registrado, diariamente, o número de plântulas emergidas (foram consideradas como emergidas as plântulas que apresentavam os cotilédones totalmente livres e normais). Quando houve estabilização da emergência, procedeu-se ao cálculo da percentagem de emergência (Labouriau \& Valadares 1976).

Aos 160 dias após a semeadura (DAS), em 11/04/2008, realizou-se a avaliação das plantas, considerando-se os seguintes parâmetros fitotécnicos: altura linear de planta $(\mathrm{cm})$, número de folhas,

Tabela 2. Resultados da análise química ${ }^{1}$ para micronutrientes, em substratos utilizados em experimento de produção de mudas de mangabeira em tubetes (Cassilândia, MS, 2008).

\begin{tabular}{ccrcll}
\hline \multirow{2}{*}{ Substratos $^{2}$} & $\mathrm{~B}$ & $\mathrm{Cu}$ & $\mathrm{Fe}$ & $\mathrm{Mn}$ & $\mathrm{Zn}$ \\
\cline { 2 - 6 } & \multicolumn{5}{c}{$\mathrm{mg} \mathrm{L}^{-1}$} \\
$\mathrm{~A}$ & $<0,01$ & $<0,01$ & 0,01 & 0,1 & 0,01 \\
$\mathrm{~B}$ & $<0,01$ & 0,01 & 0,2 & 0,2 & 0,02 \\
$\mathrm{C}$ & 0,2 & 0,02 & 0,2 & 0,01 & 0,01 \\
$\mathrm{D}$ & $<0,01$ & $<0,01$ & 0,2 & 0,5 & 0,04 \\
$\mathrm{E}$ & $<0,01$ & $<0,01$ & $<0,01$ & 0,8 & 0,1 \\
\hline
\end{tabular}

${ }^{1}$ Método de extração: 1:2 (Holanda). Métodos de determinação B, Cu, Fe, Mn, Zn: ICP-OES. ${ }^{2}$ Substrato A: areia lavada + Plantmax ${ }^{\circledR}+$ solo $(1: 1: 3$ v:v:v). Substrato B: casca de arroz carbonizada + Plantmax ${ }^{\circledR}+$ solo (1:1:3). Substrato C: casca de arroz carbonizada + húmus de minhoca + solo $(1: 1: 3)$. Substrato D: esterco bovino + Plantmax $^{\circledR}+$ solo (1:1:3). Substrato E: esterco bovino + solo (2:3). índice de clorofila foliar (CCI), diâmetro do colo $(\mathrm{mm})$, percentagem de mortalidade, comprimento do sistema radicular $(\mathrm{cm})$ e massa seca da parte aérea, do sistema radicular e total $\left(\mathrm{g}\right.$ planta $\left.\mathrm{a}^{-1}\right)$. A parte aérea foi separada do sistema radicular, para a realização das medições necessárias. O índice de clorofila foliar foi determinado diretamente por um clorofilômetro (Chlorophyll Content Meter, CCM-200, da companhia OptSciences ${ }^{\circledR}$ ), sendo considerada uma das folhas do último par de folhas completamente expandido de cada planta. A massa seca do sistema radicular e da parte aérea foram obtidas após secagem em estufa de circulação forçada de ar, a $65^{\circ} \mathrm{C}$, até atingirem massa constante.

Os dados foram submetidos a análise de variância (teste F), utilizando-se o software SISVAR (Ferreira 2003), e as médias comparadas pelo Teste Scott-Knott, a $5 \%$.

\section{RESULTADOS E DISCUSSÃO}

Houve diferença significativa para as variáveis analisadas, exceto para percentagem de emergência, diâmetro do colo e comprimento do sistema radicular (Tabela 3).

As médias do índice de velocidade de emergência (IVE) diferiram significativamente $(p<0,05)$ entre os substratos estudados, sendo que o menor valor, para esta variável, foi observado no substrato areia lavada + Plantmax $^{\circledR}+$ solo (1:1:3). Os demais substratos utilizados apresentaram valores estatisticamente iguais ou superiores, se comparados ao substrato areia lavada + Plantmax ${ }^{\circledR}+$ solo (1:1:3). No entanto, o maior índice de velocidade de emergência foi obtido para as sementes semeadas no substrato casca de arroz carbonizada + húmus de minhoca + solo 1:1:3 (Tabela 3).

O substrato areia lavada + Plantmax $^{\circledR}+$ solo $(1: 1: 3)$ apresentava, em sua composição, a areia, 
Tabela 3. Valores médios ${ }^{1}$ de percentagem de emergência (\%E), diâmetro do colo (DC), comprimento do sistema radicular (CSR), índice de velocidade de emergência (IVE), altura de planta (H) e número de folhas (NF) de mudas de mangabeira produzidas em tubetes, em função de diferentes substratos, aos 160 DAS (Cassilândia, MS, 2008).

\begin{tabular}{|c|c|c|c|c|c|c|}
\hline Substrato & $\begin{array}{l}\mathrm{E} \\
\%\end{array}$ & $\begin{array}{c}\mathrm{DC} \\
(\mathrm{mm})\end{array}$ & $\begin{array}{l}\text { CSR } \\
(\mathrm{cm})\end{array}$ & IVE & $\frac{\mathrm{H}}{(\mathrm{cm})}$ & NF \\
\hline $\mathrm{A}$ & $83,30 \mathrm{a}$ & $1,90 \mathrm{a}$ & $13,22 \mathrm{a}$ & $4,617 \mathrm{~b}$ & $5,36 \mathrm{~b}$ & $6,27 \mathrm{~b}$ \\
\hline B & $91,65 \mathrm{a}$ & $1,72 \mathrm{a}$ & $14,20 \mathrm{a}$ & $6,087 \mathrm{a}$ & $5,61 \mathrm{~b}$ & $6,02 \mathrm{~b}$ \\
\hline $\mathrm{C}$ & $94,97 \mathrm{a}$ & $2,00 \mathrm{a}$ & $13,64 \mathrm{a}$ & $7,022 \mathrm{a}$ & $8,34 \mathrm{a}$ & $9,77 \mathrm{a}$ \\
\hline $\mathrm{D}$ & $91,65 \mathrm{a}$ & $2,19 \mathrm{a}$ & $13,10 \mathrm{a}$ & $6,462 \mathrm{a}$ & $9,35 \mathrm{a}$ & $9,96 \mathrm{a}$ \\
\hline E & $95,53 \mathrm{a}$ & $2,10 \mathrm{a}$ & $13,47 \mathrm{a}$ & $6,450 \mathrm{a}$ & $8,76 \mathrm{a}$ & $9,35 \mathrm{a}$ \\
\hline Valor de F & $1,98^{\mathrm{ns}}$ & $3,46^{\text {ns }}$ & $1,73^{\text {ns }}$ & $4,43 *$ & $27,52 * *$ & $42,40 * *$ \\
\hline C.V. (\%) & 7,60 & 9,85 & 4,83 & 14,07 & 9,47 & 7,26 \\
\hline
\end{tabular}

${ }^{1}$ Médias seguidas de mesma letra, em cada coluna, não diferem entre si, pelo Teste Scott-Knott, a $5 \%$. * Significativo a $5 \%$. $* *$ Significativo a $1 \%$. ns Não significativo.

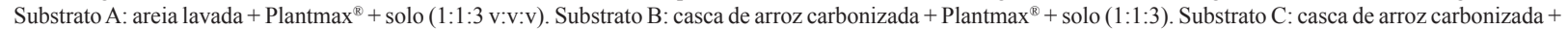
húmus de minhoca + solo (1:1:3). Substrato D: esterco bovino + Plantmax ${ }^{\circledR}+$ solo $(1: 1: 3)$. Substrato E: esterco bovino + solo $(2: 3)$.

componente com alta capacidade de drenagem, provavelmente não retendo a quantidade de água necessária para que se iniciasse o processo germinativo, o que pode ter acarretado menor IVE. Este substrato também apresentou a menor percentagem de emergência $(83,30 \%)$, apesar de não terem sido observadas diferenças significativas para esta variável, o que pode estar diretamente relacionado ao IVE, pois a semente pode ter sofrido perda de umidade, enquanto não iniciava o processo germinativo, e, sendo a mesma recalcitrante, ficou sujeita a perder sua viabilidade.

Wagner Júnior et al. (2006), trabalhando com diferentes substratos, na germinação e desenvolvimento inicial de maracujazeiro-doce, que também apresenta semente do tipo recalcitrante, não obtiveram diferença entre os substratos testados, sendo que um destes era a areia lavada, embora materiais como a areia ou a terra sejam inadequados como substratos para tubetes, devido ao seu peso e consequente desagregação (Campinhos Júnior \& Ikemori 1983).

As médias de altura de mudas de mangabeira diferiram significativamente $(p<0,01)$ entre os substratos testados (Tabela 3 e Figura 1). Os substratos que proporcionaram maior crescimento de mudas, em altura, foram o C, D e E, os quais apresentavam, em sua composição, matéria orgânica, sendo a concentração de $20 \%$ de húmus de minhoca, no substrato C, e $20 \%$ e $40 \%$ de esterco bovino, nos substratos $\mathrm{D}$ e E, respectivamente.

Costa et al. (2005), estudando diferentes substratos, para a produção de mudas de jenipapo em tubetes, observaram que o melhor desempenho de plantas, em relação à altura, pôde ser observado nos substratos que continham terra preta + esterco bovino (1:1) e terra preta + casca de arroz carbonizada + esterco bovino (1:1:1). Estes resultados confirmam a importância de uma fonte de matéria orgânica no substrato, para a produção de mudas de frutíferas em tubetes.

Em relação ao número de folhas de mudas de mangabeira, novamente os substratos C, D e E se destacaram (Tabela 3 e Figura 1), como ocorreu para a variável altura de muda.

Outros trabalhos com espécies frutíferas também obtiveram os melhores resultados para a variável número de folhas, quando utilizado substrato com matéria orgânica na forma de esterco, conforme ob-

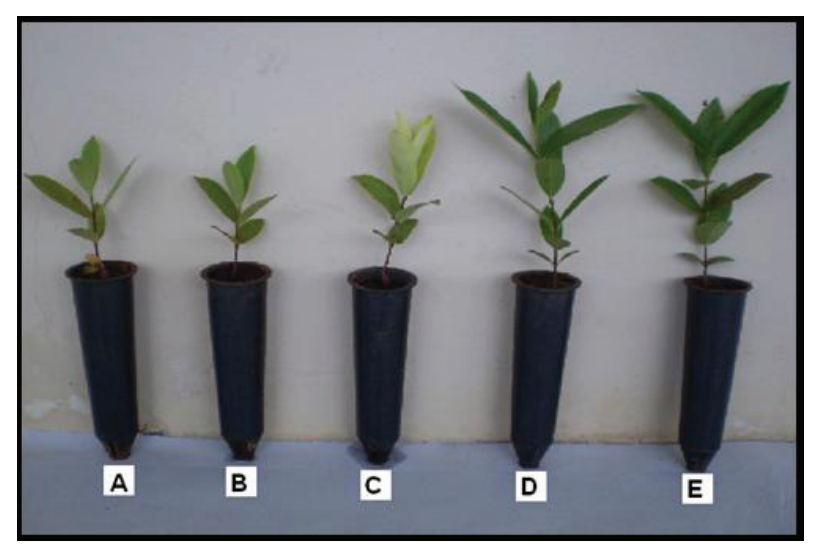

Figura 1. Mudas de mangabeira, aos 160 DAS, produzidas em tubetes, em função de diferentes substratos: A (areia lavada + Plantmax ${ }^{\circledR}+$ solo, 1:1:3 v:v:v), B (casca de arroz carbonizada + Plantmax ${ }^{\circledR}+$ solo, 1:1:3), C (casca de arroz carbonizada + húmus de minhoca + solo, 1:1:3), $\mathrm{D}\left(\right.$ esterco bovino + Plantmax $^{\circledR}+$ solo, 1:1:3) e E (esterco bovino + solo, 2:3) (Cassilândia, MS, 2008). 
servado na produção de mudas de jatobá (Carvalho et al. 2003), nespereira (Pio et al. 2004), mamoeiro 'Formosa' (Mendonça et al. 2007) e maracujazeiro (Silva et al. 2009).

Para o índice de clorofila das folhas de mudas de mangabeira, os substratos D e E apresentaram as maiores médias (Tabela 4). Nota-se que o substrato C diferiu estatisticamente dos substratos D e E, para as características índice de clorofila e massa seca da parte aérea, em se tratando de variáveis relacionadas com a parte aérea das plantas. Nas demais características da parte aérea das mudas produzidas em tubetes, o substrato $\mathrm{C}$ apresentou médias estatisticamente semelhantes às dos substratos D e E (Tabelas 3 e 4). Provavelmente, o melhor destes substratos tenha se destacado em função da sua maior fetrtilidade, devido à presença da matéria orgânica tanto na forma de esterco quanto na forma de húmus de minhoca.

Portanto, o que pode ter acarretado o baixo índice de clorofila das mudas cultivadas no substrato $\mathrm{C}$, se comparado aos substratos D e E, foi o excesso de potássio associado ao $\mathrm{pH}$ mais alcalino e aos menores teores de nitrogênio, magnésio, cálcio e enxofre (Tabela 1), neste substrato. Segundo Malavolta et al. (2002), o excesso de potássio pode provocar falta de magnésio e cálcio, pois a absorção é dificultada.

O magnésio ocupa posição central na molécula de clorofila, funciona como ativador de muitas enzimas e ajuda na absorção do fósforo. Já o cálcio faz parte da parede celular e, quando é deficiente, ocorre o colapso do pecíolo e amarelecimento das folhas mais novas, que também caem (Malavolta et al. 2002).
Em relação à massa seca do sistema radicular (MSRa), o melhor desempenho foi observado para os substratos C, D e E (Tabela 4). De acordo com Gomes et al. (1990), as mudas produzidas em tubetes apresentam o sistema radicular mais estruturado e compacto, sendo menos susceptível a lesões de manuseio e transporte. Mendonça et al. (2003) observaram que a massa seca da raiz de mudas de mamoeiro foi superior em sacos de polietileno, quando os mesmos foram comparados com tubetes $\mathrm{e}$ bandejas, e, entre os substratos utilizados nos tubetes e nas bandejas, não ocorreu diferença estatística, para esta característica.

A massa seca da parte aérea (MSPA) também apresentou médias superiores, nos substratos D e E (Tabela 4). A composição destes substratos, provavelmente, foi adequada ao desenvolvimento das mudas, pois foi favorável aos demais parâmetros de crescimento analisados anteriormente.

Para a massa seca da parte aérea de mudas de mamoeiro, Mendonça et al. (2003) obtiveram o melhor resultado, para o substrato contendo esterco de curral + carvão vegetal + solo + areia (2:1:1:1), em sacos de polietileno. Portanto, por serem a massa seca do sistema radicular e a massa seca da parte aérea superiores, nos substratos D e E, a massa seca total (MST) também teve o mesmo comportamento (Tabela 4), como era de se esperar.

Ao se determinar a massa seca de uma planta, tem-se conhecimento da intensidade de crescimento da mesma, o que está relacionado com a quantidade de nutrientes absorvida, e, consequentemente, possibilita o entendimento de fatores relacionados com a adubação (Glass 1989, Marschner 1995).

Tabela 4. Valores médios ${ }^{1}$ de índice de clorofila foliar (IC), percentagem de mortalidade (\%M) e massa seca da parte aérea (MSPA), do sistema radicular (MSRa) e total (MST) de mudas de mangabeira produzidas em tubetes, em função de diferentes substratos, aos 160 DAS (Cassilândia, MS, 2008).

\begin{tabular}{|c|c|c|c|c|c|}
\hline \multirow{2}{*}{ Substrato $^{2}$} & $\mathrm{IC}$ & MSPA & MSRa & MST & $\mathrm{M}$ \\
\hline & $(\mathrm{CCI})$ & (g) & (g) & (g) & $\%$ \\
\hline A & $10,84 \mathrm{~b}$ & $0,192 \mathrm{c}$ & $0,322 \mathrm{~b}$ & $0,515 \mathrm{~b}$ & $11,21 \mathrm{~b}$ \\
\hline B & $9,73 \mathrm{~b}$ & $0,180 \mathrm{c}$ & $0,292 \mathrm{~b}$ & $0,472 \mathrm{~b}$ & $0,00 \mathrm{c}$ \\
\hline $\mathrm{C}$ & $11,07 \mathrm{~b}$ & $0,382 \mathrm{~b}$ & $0,455 \mathrm{a}$ & $0,837 \mathrm{a}$ & $12,14 \mathrm{~b}$ \\
\hline $\mathrm{D}$ & $23,54 \mathrm{a}$ & $0,492 \mathrm{a}$ & $0,475 \mathrm{a}$ & $0,967 \mathrm{a}$ & $27,23 \mathrm{a}$ \\
\hline $\mathrm{E}$ & $22,42 \mathrm{a}$ & $0,456 \mathrm{a}$ & $0,453 \mathrm{a}$ & $0,910 \mathrm{a}$ & $30,25 \mathrm{a}$ \\
\hline Valor de F & $91,17 * *$ & $27,80 * *$ & $6,40 * *$ & $15,53 * *$ & $16,89 * *$ \\
\hline C.V. (\%) & 9,23 & 16,32 & 16,86 & 15,79 & 37,56 \\
\hline
\end{tabular}

${ }^{1}$ Médias seguidas de mesma letra, em cada coluna, não diferem entre si, pelo Teste Scott-Knott, a $5 \%$. * Significativo a $5 \%$. $* *$ Significativo a $1 \%$. ${ }^{2}$ Substrato A: areia lavada + Plantmax ${ }^{\circledR}+$ solo (1:1:3 v:v:v). Substrato B: casca de arroz carbonizada + Plantmax ${ }^{\circledR}+$ solo (1:1:3). Substrato C: casca de arroz carbonizada + húmus de minhoca + solo (1:1:3). Substrato D: esterco bovino + Plantmax ${ }^{\circledR}+$ solo $(1: 1: 3)$. Substrato E: esterco bovino + solo $(2: 3)$. 
A taxa de mortalidade das mudas de mangabeira produzidas em tubetes foi superior nos substratos D e E (Tabela 4), possivelmente por apresentarem, em sua composição, matéria orgânica na forma de esterco bovino e não terem sofrido nenhum processo de esterilização.

Os sintomas que as mudas apresentaram, antes da morte, incluíram colo com lesões marrons e aquosas, ocorrendo murcha da parte aérea, seguida da queda das folhas. Estes sintomas, segundo Manica (2002), são característicos de uma doença que ataca as plantas na fase de viveiro: a podridão aquosa, podridão do colo ou murcha, causada pelos fungos Sclerotium rolfssii Sacc. (forma imperfeita) e Athelia rolfssii (Curzi) Tu \& Kimbrough (forma perfeita).

Assim, apesar de não ter sido realizado nenhum teste de patogenicidade, para comprovar a presença deste fungo, os sintomas apresentados pelas plantas foram característicos desta doença, nos substratos que continham o esterco bovino na sua composição.

\section{CONCLUSÃO}

Os substratos compostos por casca de arroz carbonizada + húmus de minhoca + solo (1:1:3), esterco bovino + Plantmax ${ }^{\circledR}+$ solo $(1: 1: 3)$ e esterco + solo (2:3) favoreceram o desenvolvimento de mudas de mangabeira.

\section{AGRADECIMENTOS}

Ao Conselho Nacional de Desenvolvimento Científico e Tecnológico (CNPq), pela bolsa de iniciação científica concedida à primeira autora.

\section{REFERÊNCIAS}

AGUIAR FILHO, S. P.; BOSCO, J.; ARAÚJO, I. A. A mangabeira (Hancornia speciosa): domesticação e técnicas de cultivo. João Pessoa: EMEPA-PB, 1998. (Documentos, 24).

BARROS, D. I. Tecnologia de sementes de mangaba (Hancornia speciosa Gomes). 2006. 89 f. Tese (Doutorado em Agronomia)-Universidade Federal da Paraíba, Areia, 2006.

CAMPINHOS JÚNIOR, E.; IKEMORI, Y. K. Nova técnica para a produção de mudas de essências florestais. $I P E F$, Piracicaba, v. 23, n. 1, p. 47-52, 1983.
CARVAlHO, J. L. S. de et al. Produção de mudas de jatobá (Hymenaea courbaril L.) em diferentes ambientes, recipientes e composições de substratos. Cerne, Lavras, v. 9, n. 1, p. 109-118, 2003.

COSTA, C. M. C. et al. Fungos micorrízicos arbusculares e adubação fosfatada em mudas de mangabeira. Pesquisa Agropecuária Brasileira, Brasília, DF, v. 40, n. 3, p. 225 232, 2005.

EMPRESA BRASILEIRA DE PESQUISA AGROPECUÁRIA (Embrapa). Centro Nacional de Pesquisa de Solos. Sistema brasileiro de classificação de solos. Brasília, DF: Embrapa, 1999.

FERREIRA, D. F. Sisvar versão 4.3 (Build 45). Lavras: DEX/UFLa, 2003.

FERREIRA, F. R. Recursos genéticos de espécies frutíferas no Brasil. Brasília, DF: Embrapa Recursos Genéticos e Biotecnologia, 1999.

FERREIRA, M. B. Frutas comestíveis do DF (III): piqui, mangaba, marolo e mamãozinho. Cerrado, Brasília, DF, v. 5 , n. 20 , p. $22-25,1973$.

GLASS, A. D. M. Plant nutrition: an introduction to current concepts. Boston: Jones \& Bartlett, 1989.

GOMES, J. M. et al. Influência do tamanho da embalagem plástica na produção de mudas de Ipê, Copaíba e Angico Vermelho. Árvore, Viçosa, v. 14, n. 1, p. 26-34, 1990.

HIRSCHMANN, G. S.; ARIAS, A. R. de. A survey of medicinal plants of Minas Gerais, Brazil. Journal of Ethnopharmacology, Limerick, v. 29, n. 2, p. 159-172, 1990.

KÄMPF, A. N. Substrato. In: KÄMPF, A. N. (Coord.). Produção comercial de plantas ornamentais. Guaíba: Agropecuária, 2000.

LEDERMAN, I. E. et al. Mangaba (Hancornia speciosa Gomes). Jaboticabal: Funep, 2000. (Frutas nativas, 2).

LABOURIAU, L. G.; VALADARES, M. B. On the germination of seeds of Calotropis procera. Anais da Academia Brasileira de Ciências, São Paulo, v. 48, n. 2, p. 174-186, 1976.

MAGUIRE, J. D. Speed of germination aid in selection and evaluation for seedling emergence and vigor. Crop Science, Madison, v. 2, n. 2, p. 176-177, 1962.

MALAVOLTA, E.; PIMENTEL-GOMES, F.; ALCARDE, J. C. Adubos e adubações. São Paulo: Nobel, 2002.

MANICA, I. Frutas nativas, silvestres e exóticas 2: técnicas de produção e mercado: feijoa, figo-da-índia, fruta-pão, jaca, lichia, mangaba. Porto Alegre: Cinco Continentes, 2002. 
MARSCHNER, H. Nutritional physiology. In: MARSCHNER, H. Mineral nutrition of higher plants. London: Academic Press, 1995. p. 3-478.

MELO, J. T. de. Respostas de mudas de espécies arbóreas do Cerrado a nutrientes em Latossolo Vermelho Escuro. 1999. $104 \mathrm{f}$. Tese (Doutorado em Ecologia)-Universidade de Brasília, Brasília, DF, 1999.

MENDONÇA, V. et al. Diferentes níveis de composto orgânico na formulação de substratos para a produção de mudas de mamoeiro 'Formosa'. Caatinga, Mossoró, v. 20, n. 1, p. 49-53, 2007.

MENDONÇA, V. et al. Diferentes substratos e recipientes na formação de mudas de mamoeiro 'Sunrise solo'. Revista Brasileira de Fruticultura, Jaboticabal, v. 25, n. 1, p. 127130, 2003.

OLIVEIRA, P. R. A.; CARVALHO, J. G.; MACHADO, R. A. F. Efeito do fósforo e do zinco no crescimento de mudas de mangabeira (Hancornia speciosa Gomes) em casa-de-vegetação. In: CONGRESSO BRASILEIRO DE FRUTICULTURA, 15., Poços de Caldas. Resumos... Poços de Caldas: SBF, 1998. p. 543.

PARENTE, T. V.; BORGO, L. A.; MACHADO, J. W. B. Características físico-químicas de frutos de mangaba de Cerrado da região geoeconômica do Distrito Federal. Ciência e Cultura, São Paulo, v. 37, n. 1, p. 95-98, 1985.

PAULA, J. E. de. Cerrado: sugestão para a adequação entre produção e preservação. Informe Agropecuário, Belo Horizonte, v. 16, n. 1, p. 47-48, 1992.
PIO, R. et al. Efeito de diferentes substratos no crescimento de mudas de nespereira. Revista Brasileira de Agrociência, Pelotas, v. 10, n. 3, p. 309-312, 2004.

ROSA, M. E. C. da; NAVES, R. V.; OLIVEIRA JÚNIOR, J. P. de. Produção e crescimento de mudas de mangabeira (Hancornia speciosa Gomes) em diferentes substratos. Pesquisa Agropecuária Tropical, Goiânia, v. 35, n. 2, p. 65-70, 2005.

SANTOS, J. A.; NASCIMENTO, T. B. Efeito do substrato e profundidade de semeadura na emergência e crescimento de plântulas de mangabeira (Hancornia speciosa Gomes). Revista Brasileira Fruticultura, Jaboticabal, v. 21, n. 3, p. 258-261, 1999.

SILVA, E. A. et al. Efeito de diferentes substratos na produção de mudas de mangabeira (Hancornia speciosa). Revista Brasileira de Fruticultura, Jaboticabal, v. 31, n. 3, p. 925-929, 2009.

VIEIRA NETO, R. D. Cultura da mangabeira. Aracaju: Embrapa/CPATC, 1994. (Circular técnica, 2).

VIEIRA NETO, R. D. Efeito de diferentes substratos na formação de mudas de mangabeira (Hancornia speciosa Gomes). Revista Brasileira de Fruticultura, Jaboticabal, v. 20, n. 3, p. 265-271, 1998.

WAGNER JÚNIOR, A. et al. Influência do pH da água de embebição das sementes e do substrato na germinação e desenvolvimento inicial do maracujazeiro doce. Revista Brasileira de Agrociência, Pelotas, v. 12, n. 2, p. 231-235, 2006. 